\title{
Explore the Post Traumatic Growth among Cancer Patients at Selected Hospital Of Haryana
}

\author{
Poonam Ahlawat ${ }^{1}$, Rathish Nair ${ }^{2}$, A. Right Kumari Devi ${ }^{3}$ \\ ${ }^{l}$ M.Sc. Nursing, M.M College of Nursing, Maharishi Markandeshwar University, India) \\ ${ }^{2}$ Associate Professor, M.M College of Nursing Maharishi Markandeshwar University, India) \\ ${ }^{3}$ Assistant Professor, M.M College of Nursing, Maharishi Markandeshwar University, India)
}

\begin{abstract}
The experience of being diagnosed with and treated for cancer is an extremely stressful experience for most individuals. In addition to commonly recognized negative effects such as posttraumatic stress symptoms (PTSS), there may be positive personal developmental change, including posttraumatic growth (PTG). The purpose of the study was to explore the post traumatic growth among cancer patients. The study involved 100 cancer patients. The data was collected by using standardized tool-post traumatic growth inventory (PTGI) which consists of five subscales. Participants reported high spiritual strength. Only few of the patients were able to develop new possibilities which suggest that they may be beginning to make choices in a more conscious manner. The associations of post traumatic growth of cancer patients with selected demographic variables suggest that relating to others was statistically associated with gender (4.58) and marital status (4.70), spiritual strength was found to be associated with residence (4.43), religious activities (9.29) and importance of religious activities (32.74). Appreciation of life was found dependent on occupation (5.88) and annual household income (10.92) at 0.05 level of significance and the association of post traumatic growth with selected clinical variables suggest that new possibilities was statistically significant with duration of diagnosis (7.82), spiritual strength with duration of diagnosis (.95) and appreciation of life with duration of diagnosis (9.06) at 0.05 level of significance. Therefore it was concluded that majority of cancer patients after diagnosis with cancer were able to reevaluate their spiritual strength.
\end{abstract}

Keywords: Appreciation of life, Cancer, New possibilities, Patient, Personal strength, Post traumatic growth, Relating to others, Spiritual strength.

\subsection{Introduction}

\section{Introduction}

Cancer is a serious and traumatic event that impacts millions of individuals each year. Cancer is the second biggest cause of death in India, growing at 11 per cent annually. There are 2.5 million cancer cases and four lakh deaths a year in India.[1] Cancer has the ability to shake one's worldview and significantly impact one's assumption about life. The diagnosis and subsequent treatment of cancer can cause negative psychological and physical sequel that can severely impact individuals' everyday life. In addition to commonly recognized negative effects such as posttraumatic stress symptoms (PTSS) [2], there may also be positive personal developmental change, including posttraumatic growth (PTG), which occurs in conjunction with or in the aftermath of the traumatic experience. PTG has been defined as "Positive psychological change experienced as a result of the struggle with highly challenging life circumstances or traumatic events"[3].

A total of 1,638,910 new cancer cases and 577,190 deaths from cancer are projected to occur in the United States in 2012 [4].As per Indian population census data, the rate of mortality due to cancer in India is alarmingly high this was 819354 in (2004) which drastically increases to 979786 in (2010). According to the Health department officials based the calculation on the basis of a report on cancer patients prepared by PtBhagwatDayal P.G.I.M.S. Rohtak, Haryana in October 2012 stated that there are 27,827 cancer patients in Haryana [5] and a survey conducted in Punjab, the Punjab Health Minister Madan Mohan Mittal said that 23,874 cases of people suffering from cancer have been detected, the number of persons complaining of cancer symptoms were 84,453 . According to the survey, 33,318 cancer deaths have occurred during last five years, out of which 14,682 were in the Malwa region alone. As many as 4,000 of these happened in Ludhiana [6].

\subsection{Objectives of The Study}

1. To explore the post traumatic growth among cancer patients.

To determine the association of the levels of post traumatic growth with selected variables among cancer patients. 


\subsection{Research Design And Setting}

\section{Material And Method}

The study used a cross-sectional exploratory design and it was carried out between $13^{\text {th }}$ December 2012 to $12^{\text {th }}$ January 2013. The study sample consisted of 100 patients diagnosed with a variety cancer (62 male and 38 female) in who were consecutively admitted in the In-patient unit, Radiotherapy department of Post graduate institute of Medical Sciences (P.G.I.M.S) Rohtak, Haryana. They entered the study based on their acceptance to the questionnaire and willing to participate.

\subsection{Data Collection}

The data collection tools comprised an record sheet on Demographic and clinical characteristics of cancer patients, Post traumatic growth inventory. The data were collected face to-face interviews conducted by researchers in the in-patient unit of radiotherapy department. The researchers introduced the questionnaire to the participants and explained the material covered. The average time for completing the questionnaires was 30-45 minutes.

\subsection{Data Collection Instrument}

The tools which were used in present study comprised of 2 sections: Demographic and clinical variables, post traumatic growth inventory

\section{Section 1: Demographic and clinical variables}

Part 1.1- It consisted of the record sheet which was constructed to collect data regarding patients characteristics age, gender, residence, education, occupation, annual household income, marital status, present position in the family, importance of religious activities.

Part 1.2- consists of diagnosis of cancer, duration of diagnosis, stage of disease and ongoing treatment.

\section{Section 2: Post Traumatic Growth Inventory (PTGI)}

The Posttraumatic Growth Inventory is a 21-item self-report measure, which assesses positive outcomes related to cancer. Participants will be asked to rate the degree to which they experienced a certain change in their life as a result of their experience with cancer diagnosis. Each item is rated on a six-point Likert scale ranging from 0 ("I did not experience this change") to 5 ("I experienced this change to a very great degree"). Reliability score for hindi version was .94. The 21 items were under five subscales including Relating to Others, New Possibilities, Personal Strength, Appreciation of Life, and Spiritual Change. The range of scale score is $0-105$. The higher score of the scale mote will be the post traumatic growth [7-8].

\subsection{Ethical Considerations}

Regarding ethical considerations, the ethical approval was obtained from the Institutional Ethical Committee Maharishi Markendshwar University and formal approval was obtained from the H.O.D of Radiotherapy department P.G.I.M.S, Rohtak. Written information was given to the participants and their oral consent was obtained. The patients were informed about the purpose of the research and assured of their right to refuse to participate in or to withdraw from the study at any stage. Anonymity and confidentiality of subjects' data were guaranteed.

\subsection{Statistical Analysis}

Data was analyzed and interpreted by employing descriptive and inferential statistics. SPSS version 16.0 was used to analyze the data. $\mathrm{P}$ value $\leq 0.05$ was considered as significant.

\section{Results}

About (51\%) of the cancer patients were belonged to age group of 48-62 years, $(62 \%)$ of the patients were male most of them $(78 \%)$ of the were residing in rural area, $(45 \%)$ of the patients were illiterate. Majority of $(91 \%)$ were self employed. Most of the patients (63\%) belong to income group of 50001-100000/- .The majorities $(93 \%)$ of the patients were married and (67\%) were adults. Most of $(58 \%)$ of the patients were those who does religious activities once in a day and $(51 \%)$ of the patients had a great importance of religious activities. most of the patients (29\%) were diagnosed were Ca Cervix and only (3\%) were diagnosed with breast cancer. Most of cancer patients (57\%) had duration of diagnosis between 6months-1year, Most (50\%) of cancer patients were in III stage of the disease. With regard to the type of treatment received $(51 \%)$ received chemotherapy as the treatment.

The total score for post traumatic growth inventory was $55.29 \pm 18.0$ 


\section{Frequency and Percentage Distribution of Cancer Patients According To Post Traumatic Growth Scores N=100}

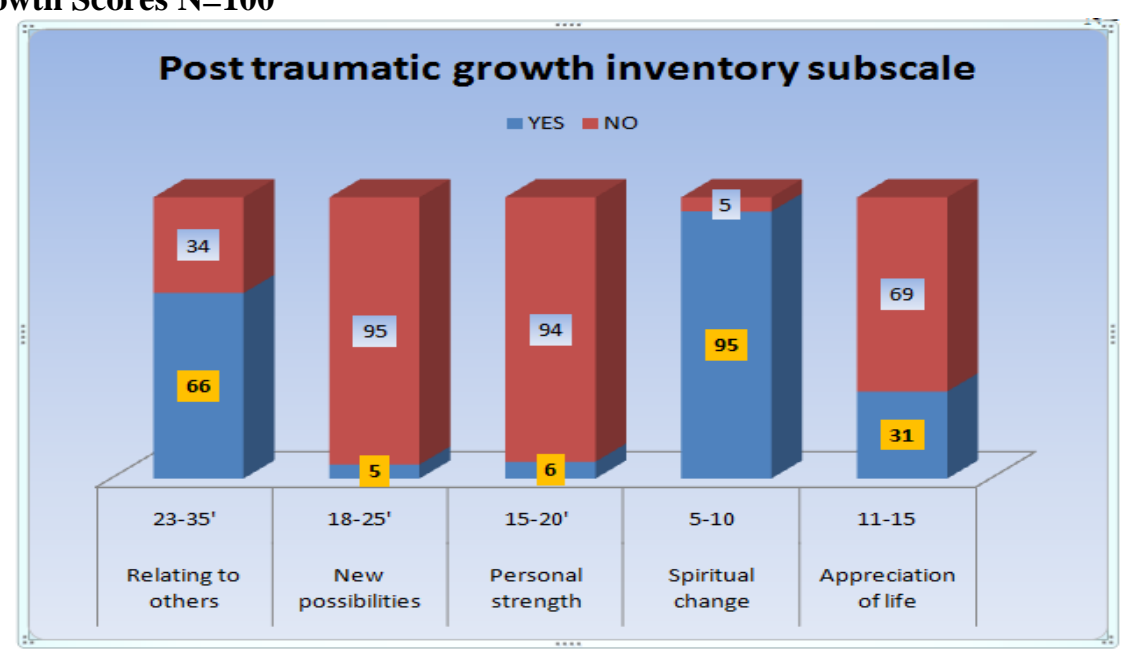

Data presented in the bar graph revealed that majority (95\%) of the cancer patients were using spiritual strength subscale of post traumatic growth inventory which suggest that they may be reevaluating spiritual beliefs, associating with a community of similar believers, or connecting with your spiritual roots. Cancer patients Only $(5 \%)$ of the patients were using new possibilities subscale which suggests that they may be beginning to make choices in a more conscious manner according to a plan and also trying to change things that need changing. It was concluded that majority of cancer patients after diagnosis with cancer were able to reevaluate spiritual strength and develop spiritual belief.

Table 1: Mean, Mean \%, Standard Deviation and Ranking of Post Traumatic Growth Scores of Cancer Patients on Post Traumatic Growth Inventory. $\mathbf{N = 1 0 0}$

\begin{tabular}{lllccc}
\hline Subscales & Possible scores & Obtained & Score & & \\
\hline & Max. & Range & Mean & Mean \% & Ranking \\
& Score & & & $23.35 \pm 5.90$ & 66.71 \\
Relating to others & 35 & $1-32$ & $8.24 \pm 5.93$ & 32.96 & II \\
New possibilities & 25 & $0-19$ & $7.16 \pm 5.03$ & 35.80 & V \\
Personal strength & 20 & $0-17$ & $7.85 \pm 1.75$ & 5.50 & IV \\
Spiritual strength & 10 & $0-10$ & $5.69 \pm 3.38$ & 53.93 & I \\
Appreciation of life & 15 & $0-14$ & $5-85 \pm 18.09$ & III \\
Total & 105 & $5-85$ & & 52.66 & \\
\hline
\end{tabular}

\section{Findings Regarding Association Of Post Traumatic Growth With Selected Variables:}

The association of post traumatic growth (relating to others, new possibilities, personal strength, spiritual strength and appreciation of life of) cancer patients with selected demographic variables (age, gender, residence, educational status, occupation, annual household income, marital status, position in family, religious activities and importance of religious activities) were analyzed using chi square and found that relating to others was statistically significant with gender (4.58) and marital status (4.70), spiritual strength was found to be associated with residence (4.43), religious activities (9.29) and importance of religious activities (32.74). Appreciation of life was found dependent on occupation (5.88) and annual household income (10.92) at 0.05 level of significance.

The association of post traumatic growth (relating to others, new possibilities, personal strength, spiritual strength and appreciation of life of) cancer patients with selected clinical variables (diagnosis, duration of diagnosis, stage of disease and ongoing treatment were analyzed using chi square and found that new possibilities was statistically significant with duration of diagnosis (7.82), spiritual strength with duration of diagnosis (.95) and appreciation of life with duration of diagnosis (9.06) at 0.05 level of significance.

\section{Discussion}

It was observed that $(51 \%)$ of the subjects belonged to the age group of 48 years and above. The findings were similar to findings reported in literature by McPherson, Steel and Dixon (2000) i.e. the incidence of breast cancer increases with age and it is common among the age group of above 40 years [9].

Analysis of the post traumatic growth inventory suggests that $(95 \%)$ of cancer patients were using spiritual strength as a factor in post traumatic growth which was found consistent with findings of (Aimee M. Moore et 
al.) which revealed that the cancer patients who use prayer as emotional outlet have reported higher post traumatic growth [10].

In present study the mean for post traumatic growth was found to be high (55.29) which was consistent with the findings of Rahmani A, Mohammadian R, Ferguson C et al. that the mean for post traumatic growth of cancer participants was (76.1) [7].

There was significant association between gender and post traumatic growth (4.58) which was found inconsistent with the study conducted by Rahmani A, Mohammadian R, Ferguson C et al. that there was no statistically significant association between gender and level of posttraumatic growth [7].

There was a significant association between female gender and post traumatic growth which was found consistent with the findings of Diana Zwahlen, NielsHagenbuch, Margaret I. Carleyet al. female participants scored higher on PTGI than males [11].

There was significant association between post traumatic growth and radiotherapy as treatment $(r=5.06)$ which was consistent with the findings of Rahmani A, Mohammadian R, Ferguson $\mathrm{C}$ et al. that there is significant association between post traumatic growth and history of treatment by radiotherapy $(t=2.1, p=0.03)$ [7].

\section{Conclusion}

Most of the cancer patients stated that spiritual belief contributed to the process of growth by providing a foundation for meaning to be accessed from within one's experience. This foundation allowed for both a deepening of experience, an exploration of new spiritual potentialities and the application of previous beliefs to ones current circumstances. Spiritual strength has deepened and made real through journey with cancer.

\section{Implications For Nursing Practice}

Cancer is not only a medical problem; it also involves psychological, emotional and social problems. As nursing personnel are direct care providers and play a pivotal role in the treatment and rehabilitation of patients with cancer. Post traumatic growth subscales act as a helping aid as it helps them to have a better understanding of the patient psychological aspect and act as a guide to promote welling being of the patient. It helps them to gather more valuable data about the health of the patient and plan care accordingly.

\section{Limitations}

1. The data for assessing post traumatic growth (PTG). was collected at one point of time while it should be done after an interval of time.

2. In present study only ongoing treatment was assessed, previous treatment was not assessed.

3. Dietary pattern and tobacco eating behavior of cancer patients was not assessed.

\section{References}

[1]. DamayantiDatta. When lifestyle spells disaster.India today. 2010 August 13 available from: http://indiatoday.intoday.in/story/whenlifestyle-spells-disaster/1/108803.html

[2]. Artherholt SB, Fann JR. Psychosocial care in cancer. Current Psychiatry Reports 2012; 14(1):23-29.

[3]. Matthew Tull. Posttraumatic Growth. Medical Review Board 2009 nov, 9available from: http://ptsd.about.com/od/glossary/g/ptsdgrowthdef.htm

[4]. Siegel R, Naishadham D, Jemal A. Cancer statistics. 2012. 62(1):10-29.

[5]. Das B.P Cancer pattern in Haryana: twenty one year experience, Health Administrator (17), 1: (29-49). Available from: http://medind.nic.in/haa/t05/i1/haat05i1p29.pdf

[6]. Kavithakuruganti. Punjab in grip of cancer, over 33000 died in last five years: Door to Door Census results. 2013, Jan; 29. Available from: http://www.indianexpress.com/news/punjab-in-grip-of-cancer

[7]. A Rahmani, R Mohammadian, C Ferguson, L Golizadeh, M Zirak, H Chavoshi. Posttraumatic growth in Iranian cancer patients. Indian Journal of Cancer 2012 Dec; 49(3): 287-92.

[8]. DeryaTanriverdSavas E, Ganime Can. Post traumatic growth in Turkish patients with cancer. Asian pacific journal of cancer prevention. 2012; 13 (9): 4311-4314. doi: 10.7314/APJCP.2012.13.9.4311.

[9]. Mc. Pherson K, Steel C M, Dixon JM. ABC of breast diseases.Breast cancer epudemilogy, risk factor and genetics. British Medical Journal, 2007 321(9), 624-628.

[10]. Aimee M. Moore, T. Clark Gamblin, David A. Geller, Michael N. Youssef,Kristin E. Hoffman, Leigh Gemmell, Sonja M. Likumahuwa, Dana H. Bovbjerg, Anna Marsland, Jennifer L. Steel. A Prospective Study of Posttraumatic Growth as Assessed by Self Report and Family Caregiver in the Context of Advanced Cancer.Psychooncology. 2011 May; 20(5): 479487.doi: $10.1002 /$ pon.1746.

[11]. Diana Zwahlen, NielsHagenbuch,Margaret I. Carleyet al. Posttraumatic growth in cancer patients and partners-effects of role, gender and the dyad on couples' posttraumatic growth experience Psycho-Oncology 2010; 19,(1): 12-20. 